\title{
The mutual constitution of risk and inequalities: Intersectional risk theory
}

\author{
Anna Olofsson ${ }^{\mathrm{a}}$, Jens O. Zinn ${ }^{\mathrm{b}}$, Gabriele Griffin ${ }^{\mathrm{c}}$, Katarina Giritli Nygren ${ }^{\mathrm{d}}$, Andreas Cebulla ${ }^{\mathrm{e}}$ \\ and Kelly Hannah-Moffat ${ }^{\mathrm{f}}$

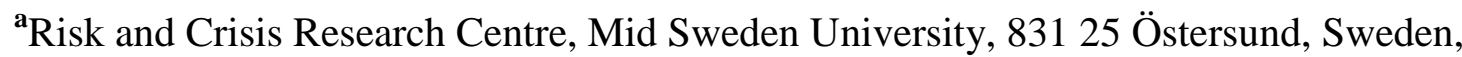 \\ ${ }^{\mathbf{b}}$ School of Social and Political Sciences, University of Melbourne, Australia, ${ }^{\mathbf{c}}$ Centre for \\ Women's Studies, University of York, UK, ${ }^{\mathbf{d}}$ Forum for Gender Studies, Mid Sweden \\ University, Sweden, ${ }^{\mathbf{e}}$ National Institute of Labour Studies, Flinders University, Australia, \\ ${ }^{\mathbf{f}}$ Centre of Criminology \& Sociology Studies, University of Toronto Mississauga, Canada.
}

Published in:

Health, Risk \& Society

Special Issue: Risk and Social Theory

Volume 16, Issue 5, 2014, pages 417-430

DOI: $10.1080 / 13698575.2014 .942258$

- $\quad$ Received: 17 Mar 2014

- $\quad$ Accepted: 3 Jul 2014

- $\quad$ Published online: 24 Jul 2014

Key words: risk theory, intersectionality, inequality

\begin{abstract}
This article examines the conceptual importance of integrating risk and intersectionality theory for the study of how risk and various forms of inequality intersect and are mutually constitutive. We argue that an intersectional perspective can advance risk research by incorporating more effectively the role of such social categories as gender and race into the analysis of 'risk' as an empirical phenomenon. In doing so, it articulates more clearly the connection between the social construction of risk with, on the one hand, the reproduction of new and complex social inequalities and, on the other, intersections of social class, gender, ethnicity, and other social categorizations. The article traces the intellectual division between risk and feminist-inspired intersectionality research, showing how these approaches can be aligned to study, for example, risk-based welfare and social policy. This case is used to illustrate how an intersectional perspective can reveal the ways in which new governance strategies create new divisions and reproduce existing forms of social inequality. The article concludes with a call for a new research agenda to integrate intersectional frameworks with
\end{abstract}


risk theory in order to provide a more nuanced analysis of the relationship between social inequality and risk.

\section{Introduction}

Framing social problems in terms of risk has become a common strategy for managing complex social changes at national and international levels. As a consequence, the actions of social institutions that, for instance, deal with social challenges through welfare interventions or social inclusion initiatives are being transformed by the use of risk discourse and risk management practices. Thus, 'social problems', often associated with particular categories of 'vulnerable' people, are redefined, reframed, and—ultimately—managed as 'risks'.

Whilst risk research has developed its own critical, structuralist theoretical frame to describe the social construction of risk, its understanding of the complex multi-dimensionality of the social relations that shape the lived experience of risk is limited. Explicitly socio-structural explorations of risk have remained strangely one-dimensional. Several scholars have studied the inter-relationship between risk and gender (Hannah-Moffat and O'Malley 2007), risk and class (Cebulla 2007), risk and age (Wall 2014), or risk and race (Finucane et al. 2000). But an analytical and integrating discourse that acknowledges the connectedness of these dimensions and the influence of their interactions on the representation, production, and reproduction of risk in society remains an as yet unrealized ambition. Intersectional approaches to the study of social phenomena, we will argue here, have the potential to offer a more telling account of inequitable social relations (Giritli Nygren and Olofsson, forthcoming). The objective of this article is therefore to explore the interrelations between risk and social inequality by adding an intersectional perspective to the analysis of risk, which in turn can help us better understand the regulatory strategies that reproduce old and produce new inequalities, and in turn can help to explain internationally observed increases in social inequality.

Intersectional concepts and research are defined by their focus on 'categories of difference in individual lives, social practices, institutional arrangements and cultural ideologies, and the outcome of these interactions in terms of power' (Davis 2008: 68; emphasis added). Intersectionality is explicit in acknowledging, examining, and working with the multidimensionality of the social relations that define people's daily lives and the functioning of social systems. It is thus also a critical tool for understanding the social construction of risk and of social and economic inequality. Yet, an early scan of key risk journals (Health, Risk and Society, the Journal of Risk Research, Risk Analysis, and Risk, Hazards \& Crisis in Public Policy) revealed no systematic use of intersectionality as a theoretical concept in its own right in risk research. The same was true for a range of sociological journals (BioSocieties, British Journal of Sociology, Economy \& Society, Journal of Discourses \& Governance, Sociology, Theory, Culture and Society). In these journals, authors analyse social class, gender, and race in relation to sociological risk theory (Beck 2013; Green and Singleton 2006) and empirical studies of 'at risk' or 'risky' individuals (Frigerio, Montali and Fine 2013). Yet whilst sociology thus addresses the conceptual strength of risk from different theoretical perspectives, it seems to have turned a blind eye to intersectionality and feminist 
approaches to research in general, and methodology in particular (Hannah-Moffat and O'Malley 2007). ${ }^{1} \quad$ These approaches are particularly helpful in detailing how conceptualizations of risk are shaped simultaneously by race, ethnicity, gender, social class, and other social divisions, and how risk-based policies and the governance of risk have varied and unequally affected, diverse populations. A brief example illustrates this well. The current conflict in Iraq that pits state forces against the emergent ISIS group (fighting for an 'Islamic State of Iraq and Syria') has rekindled debates about the social origins of participant Britishborn Jihadists in that conflict. These debates, not for the first time, have revealed the fallacy of the dominant social discourse that has perceived materially deprived, marginalized male youths as those primarily at risk of Islamic radicalization (Amoore and Goede 2008). The realization that these fighters often come from middle-class, highly educated backgrounds and increasingly include women as well as men has cast the debate in a new light. It has also exposed a conceptual vacuum as social commentators struggle to analyse and understand this new social risk.

This article thus makes a case for bringing together risk analysis and intersectionality to address such conceptual deficiencies in the sociology of risk. The point of intersectionality and, indeed, the argument put forward in this article, is that our conceptual framework must adapt more proactively to the emergence of ever more complex social changes and risk phenomena - and that intersectionality provides one such tool.

In the following section we begin by discussing the state of risk research and research on intersectionality. Utilizing a welfare policy case, we then exemplify how research can be advanced by combining these approaches. We conclude with a call for a new research agenda that overcomes the opposition of risk-based and socio-structural-based inequalities in order to better understand new inequalities observable in recent decades. We will illustrate how intersectionality can be employed as a conceptual and analytical tool to deepen our understanding of the structured inequity of the realities and governance of risk in late modern society. Intersectionality is an analytical shift from an additive model of factors of social inequality, and theoretically it signifies the importance of including the perspectives of multiply marginalized people and of analysing unmarked categories and how power and privilege, as much as disadvantage, is constituted (see McCall 2005). It highlights the necessity of an analysis of the construction of risk, not only from the perspective of discourses that interpolate individuals into certain subject positions, but also from a perspective that acknowledges the power dimensions of risk constructions, and that the performativity of risk takes place along lines of difference. Therefore, we argue that risk objects are intercategorized with gender, sexuality, ethnicity, and other relations of power dependent on time and place, and have to be analysed as such.

\footnotetext{
${ }^{1}$ Except for feminist approaches black feminism, gender studies, critical white studies, queer theory, masculinity studies have all contributed to the development of the intersectional approaches but few social theories about risk have been influenced by or addressed these approaches (Hannah-Moffat \& O’Malley 2007).
} 


\section{Risk theory and inequality}

Sociological theories of risk and uncertainty have a poor track record of theorizing the complexities in the reproduction of social inequalities, instead often reverting to attributing 'new inequalities' to exposure to singular, natural risks (for example, epidemics spreading through increased mobility) at the expense of examining the role of social factors, such as class or gender. It is worth noting that empirical risk research studying - for example, risk perception and individual understandings of risk - often use gender and/or race as explanatory factors in quantitative research (for example, Cebulla 2007; Finucane et al. 2000; Olofsson \& Rashid 2011a,b), and as hermeneutic categories in qualitative research (Seale 2002; Olofsson \& Öhman 2007). Particularly in (public) health-risk research there is a recognition of both inequality and diversity in terms of gender, race, and ethnicity, often explored separately on an individual (Lippman 1999, Järvinen 2012) or aggregate level (Marmot 2004), but there is also the growing literature on the more fluid nature of sex and gender, viewing gender as a social site and a determinant of health that is shaped by constant interaction with other determinants (Dworkin 2006, Edge 2013, Hankivsky and Christoffersen 2008). Although this research clearly applies a gender, class, or race perspective, or in some cases even an intersectional approach, the theoretical conceptualization of health and risk is often limited and treated as fixed categories - something that becomes problematic when examined within an intersectional framework (Olofsson and Giritli Nygren forthcoming). Similarly, sociological empirical risk research tends to lean towards the theoretical perspectives of risk society, cultural theory, and governmentality, none of which problematize intersecting inequalities in terms of gender, class, and race, but tend to avoid or find alternative explanations to societies stratification and power relations.

This perspective has been stated most explicitly in Beck's hypothesis of the increasing importance of risk conflicts 'beyond class and status', driven by 'coalitions of anxiety' rather than social class (Beck 1992: 49, 100). However, despite an ample critique of the weak conceptualization of social inequality in risk studies (Mythen 2004) and an increasing acknowledgement of the role of socio-structural factors in exposure to and experience of risk (Beck 2009), sociological theories of risk and intersectionality have developed separately. As a result, the multi-dimensional effects of individuals' lived experiences (Crenshaw, 1989:139) and the processes by which risk-based policies and institutional networks perpetuate inequality in complex ways (see Hae Yeon and Ferree 2010) remain underdeveloped in risk theorization. Consequently, there are significant gaps in our understanding of how social inequality is reproduced and how risk has been transformed in recent decades. Risk research thus lacks a clear understanding of the implications of such transformations for conceiving of and intervening in social problems.

From a critical perspective, neither risk nor inequality occurs 'naturally' in a given society. Risks and social differences are shaped and made relevant through complex social processes that express power structures, different social values, conflict over knowledge, and social differentiation, and are guided by emotions (Zinn 2008). In order to understand the new complexities of the (re)production of social inequalities in modern societies, we have to reconstruct how they combine in the description and management of social problems as risks, 
and as a result identify certain social problems while producing and legitimizing ways of dealing with others.

Public risk debates quickly objectivize social problems as risks that require and legitimize particular ways of dealing with them-read eradicating them. Sociological approaches to risk have developed as a critique of an uncritical technical and positivist understanding of risk. Rather than seeing risk as an objective danger that can be dealt with rationally on the basis of objective technological knowledge, early anthropological research emphasized that the risks we identify, the way we perceive them, and our responses to them are determined by our institutions and social values (Douglas 1992; Douglas and Wildavsky 1982). Opposing rational-choice approaches, Douglas criticised the narrow decontextualised model of utility maximisation provided by economics by arguing that it is our values that structure what we see as risky and how we respond to it. Through the distinction between self and other societies, organisations and social groups we construct and maintain our identity. The 'other' or 'otherness' is perceived as a risk (or blamed for causing or presenting risk) and the protection against it (and the other) helps to maintain group boundaries, cohesion, and integrity (Joffe 1999). In so doing, the other is usually seen as amoral, and tends to be stripped of human rights (for example, Vietnamese 'boat people' arriving in Europe or Australia in the 1970s and 1980s, and more recent Indonesian migration to Australia). While this perspective emphasized the importance of the socio-cultural determination of the social management of risk and the significant difference of socio-structural positioning (at the centre, on the periphery), it did not emphasize the analysis of how significant differences of socio-structural positioning intersect with for example, gender and class. Even though singling out particular social groups as 'risky others' has become a common tool in public debate, used to shift risks to often already marginalized or weak social groups, at the time, Douglas used her approach to understand the nature of social responses to new risks, yet omitting any scrutiny of how old and new inequalities were (re)produced in the process.

With a risk society perspective, the focus on culture shifted. While the epistemological/ontological status of risk was still an issue, the risk society perspective directly challenged class theory by questioning the social dominance of its categories and their usefulness for understanding current social conflicts (Beck 1992, 2009). Beck queried the controversy about the binary of constructivist and realist approaches with his claim that the (socially perceived) quality of new mega risks indicated a shift in the ontological nature of the risks we face, while our understanding is based on the complex interactions of different societal forces in the past ('relations of definition'). Beck (1992: 55, 100) also challenged class theorists with his hypothesis that social conflicts would increasingly develop around the allocation of risks ('coalitions of anxiety') rather than the allocation of wealth ('social class'). He was heavily criticized for his statement that new risks were somehow 'democratic' since nobody could escape climate change, genetically modified food, and so no, even though rich people might have more resources to try to do just that (Mythen 2004; Skelton 2005). Beck's claim that inequalities would be individualized, and as such would increase, found some support in the critique of feminist and gender research, which had revealed that homogenizations of socio-structural categories, such as gender, class, sexuality, and ethnicity 
(for example, Butler 1990, Knapp 2005) ignored the huge variations that resulted from complex interactions between such socio-structural factors (Frerichs 2000; McCall 2005). However, his claim sits uncomfortably with the assumption of significant continuities of socio-structural factors shaping people's lives, if in more complex forms than before.

Beck's notion of a new move towards individualization after the Second World War challenged class theorists. Contrary to class theory, Beck hypothesized that individuals would liberate themselves from old institutions while they were reintegrated by welfare states and markets that increasingly exposed them to forces beyond their control. Social institutions would increasingly approach individuals as autonomous life-planning agents, detached from traditional support mechanisms originally put in place to protect the 'unshackled' labour force from the destructive forces of Fordist and pre-Fordist capitalist production (for example, welfare provision, trades unions, and free health care). Social inequalities might yet soar as a result of these new forms of social inequality beyond class and status and, indeed, they have (McCall 2001; Sassen 1999; Piketty 2013).

However, it remains unclear to what extent old and new risks overlap in a risk society. Beck's contribution emphasizes the impact of both new risks and processes of individualization for the reproduction of social inequalities. But no attempt has been made to provide a deeper understanding of the mechanisms of old and new inequalities overlapping when reproducing and transforming social structures.

Similarly to Beck's challenge to the old class orthodoxy, the governmentality perspective on risk, building on the work of Foucault, questioned dominant, top-down power concepts (for example, Dean 1999; O’Malley 2004; Rose 1999). Power was conceptualized as increasingly exercised indirectly through discourses and calculative technologies. Actuarial risk and its embeddedness in power discourses became a key element in understanding how the generation of knowledge and dominant discourses integrates with the exercise of power. However, although power and mechanisms of government are central to understandings of risk from a governance perspective, we again see only a rudimentary understanding of the nature of the reproduction of social inequalities within this theoretical framework (HannahMoffat 2012; Hannah-Moffat and O’Malley 2007).

Intersectionality, with its basis in post-structuralist critiques of the subject as decentred and its focus on the imbrications of multiple, differentially significant social categories, offers a tool with which to close this analytical and conceptual gap. Intersectional theory's understanding of often taken-for-granted identities as, in fact, the product of multiple and multi-layered axes of difference has the potential to add detail and, thus, value to the research on social risk phenomena in complex and nuanced ways (Henne and Troshynski, 2013). In the next section, intersectionality and its application to risk are further explored and developed using case studies of social and welfare policy. 


\section{The mutual constitutions of risk and inequality}

Intersectionality as a concept was popularized by Kimberlé Crenshaw (1989) to account for the ways race, gender, and class intersect to position black women in particular ways vis-à-vis the law. Here the interrelation and, importantly, the imbrication of social categories becomes immediately evident, and it is this, variously explored by a number of scholars, which is at the heart of the use of intersectional theory across a range of contexts (Signs 2012). In discussing intersectionality as a theoretical-methodological tool, Yeon Choo and Marx Ferree (2010) emphasize three dimensions of intersectionality: the importance of including the perspectives of multiply marginalized people (this builds on Crenshaw); the analytical shift away from an additive model of social categories as constructing degrees of oppression (black, female, disabled) to an analysis of the interactions of these categories; and a willingness to see multiple categories as overlapping (see McCall 2005). Intersectionality thus refuses the singling out of one particular category as determining risk in favour of understanding the overlapping dimensions of inequality as being constitutive of risk. Implicit in this is the complex understanding that different dimensions of intersecting categories of oppression matter differently according to the context. Access to medication, sanitation, and good food, for example, differentially distributed across gender and age groups in many countries, is a determining factor in the likelihood of becoming infected with tuberculosis, as is poor housing. Depending on these intersections, different people are at diverse degrees of risk of getting this illness and of having access to its cures. This is not just a matter of individual positioning, but of socio-structural differences that are manufactured through the use of particular framing devices, including risk technologies. Bringing intersectionality more directly into risk theory can clarify how such new configurations of risk produce new inequalities while old structures persist. In fact, we propose that inequalities are manufactured by modes of governance, including the use of 'risk' as a regulatory regime, that are shaped by intersectional power (im)balances.

Hannah-Moffat (2004) uses the insights of intersectionality theory to explore a more nuanced analytical account of the linkages between inequality, risk, and crime control. She shows how legal cultures use and combine risk and welfare strategies to manage diverse risky and at-risk populations. In her studies intersectionality is of particular value for disentangling the way inequalities are embedded in positivist risk frameworks, and for destabilizing categories and persons across time and space (see Henne and Troshynski 2013). Her research indicates how the integration of intersectional analyses of risk allows for a clearer articulation of how risk logics can produce a disjuncture between subjects and their experiences. It explores how different legal, therapeutic, and community conceptions of risk intersect in criminal justice decision-making practices. A variety of criminal justice strategies are used to identify and target different types of offender populations, but these are connected to a multitude of national norms, essentialist definitions, mischaracterized 'differences', and structural inequalities such as race, ethnicity, immigration class, and gender, which nuance the needs that populations express, their risks, and the types of policy interventions used. HannahMoffat (2010) and Hannah-Moffat and Maurutto (2008, 2010) thus use an intersectional risk theory to show how the new configuration of need/risk results in broader race/genderstructured relations. Political discourse, however, often ignores these structured relations or 
reconstructs them as individual failures or inadequacies, thus consolidating these same structures by fiat.

Intersectionality highlights the importance of analysing marked as much as unmarked categories of difference, and the power, status, and privilege, but also disadvantage that emanate from them. By extension, risk, rather than being seen as a set of rigid categories, can be construed and (re)produced in power relationships. Risk is intrinsically connected to the processes by which the norms of gender, ethnicity, and class are socially, performatively, and intersectionally inscribed in language, minds, and bodies (Butler 1990, Giritli Nygren and Olofsson forthcoming). To explore risk within social discourses and practices, and within the context of power, we focus on practices that simultaneously (re)produce and obfuscate sociopolitical norms and positions, as they occur in contemporary, hierarchical relations of power and knowledge (see, for example, Hannah-Moffat and O'Malley 2007; Giritli Nygren and Fahlgren 2013; Rose 2008). Thus, we explore the expression, signification, and operation of risk in particular political contexts, and how they structure action and thought as well as power relations.

The intersectional approach has not been without its critics. Marxist feminism argues that class is qualitatively different from gender and race, and cannot be considered as just another system of oppression. Others argue that intersectionality merely articulates difference, resulting in a fragmentation and stagnation of political activity. Some criticize intersectionality for not seriously problematizing the use of categories, and that its reliance on categories makes it fall into the trap of empiricism since, it is argued, the category of marginalized women employed by this theory is assumed to lead to 'authentic' knowledge (see, for example, Ferguson 2012; Mitchell 2013). Crenshaw (2011) has responded to these criticisms, pointing out that such categories can be empowering, and arguing that even if they were socially constructed, this would not negate the real effects they have on people's lives.

\section{Risk discourses in welfare policy: Responsibilization and emerging new (in)equalities}

In this section, we want to give a brief example of how intersectional theory can usefully be employed to enhance our understanding of everyday social and political processes. Our example is that of welfare policy and, specifically, the approaches of social policy to notions of 'otherness' or 'outsiderhood'. At the heart of this policy discourse are concepts of an 'atrisk' population and a 'risky' population. The former need support and guidance to help them return to the social mainstream; the latter need isolating in order to protect the mainstream from their influence. The application of these concepts reconfigures social relations through blame and responsibility/responsibilization - a process that simultaneously challenges and dynamically maintains these same social relations. The use of risk discourses also potentially creates an imbalance as it overtly expresses difference, thus bringing it to the fore. By combining the power and privilege perspective of intersectionality with the understanding of how risk is constructed of risk theory, we can better understand the relation between risk and 
inequality and perhaps even when, where and how these relations are particular strong or imbalanced.

Globally, welfare reforms that have monetized social relationships through user-pays and feefor-service arrangements, and have subjected the provision of welfare services to market principles, appear to support this view (Le Grand 1997, Handler 2004). Activation policies and the changing ethical foundations of welfare have also created competing discourses of responsibility in different welfare-settings in the shift from welfare to workfare, as well as in individual responses (Dean 2006). The penetration of market relations and of abstract systems into every aspect of the life-world compels the individual to choose. At the same time these processes promote forms of market and institutional dependency. Each individual is to be her own political economy - an informed, self-sufficient consumer of labour markets, personal security markets, and other consuming interests. Within a regime of responsible risk-taking, all differences, and the inequalities that result from them, are seen as a matter of choice (Shamir 2008). Hence, governmental risk management (intended to reduce uncertainty about future national welfare obligations) has offloaded responsibility for welfare procurement and use onto the private consumer. Conditional welfare services now link welfare entitlement to increased personal contributions, extended working lives, and in the case of unemployment benefits, active job search (Crisp 2008). Targeted, selective welfare reforms based on concepts of responsibility and reciprocity have become means for creating, sustaining and disciplining a marginalized, sometimes ghettoized 'reserve army of labour' or 'precariat' (Standing 2010; Piven and Cloward 1993; Wacquaint 2009). Whether strategic and intentional or not, welfare reforms have effectively identified and singled out new 'at-risk' and 'risky' populations, including migrants, single parents, people with disabilities, the longterm unemployed, older workers, (early) retirees, and adolescents (Cebulla et al. 2005, Cumming and Caragata 2011, Dorey 2010).

These reforms have met with varying degrees of success, and are often ineffective in sustaining employment gains, reducing welfare payments, increasing private welfare, or redressing poverty (Card et al. 2010; Cebulla et al. 2005). Reforms have also become divisive, targeting specific populations as 'at-risk' or 'risky', including migrants, single parents, older workers, (early) retirees, and adolescents (Dorey 2010), as well as substance abusers, offenders and ex-offenders, and asylum-seekers (ASRC 2013; Sutton et al. 2004). Together, the public identification of these populations and the socially differential effects of reforms threaten to create new layers of 'risky' populations along intersections of gender, ethnicity, and class (Giritli Nygren \& Fahlgren 2013; Kelly 2007, 2010). Governments and conservatives use welfare myths, such as exaggerated claims of benefit fraud and racialized depictions of dependency, to justify less generous, more exclusive, and more conditional welfare (Prenzler 2011; Sandberg 1998; Lundström 2013; Mirchandani and Chan 2007). Against the background of growing social inequality across OECD countries, public policy follows and enforces public attitudes that, internationally, have become less sympathetic toward marginalized populations (Fetzer 2011; Zatz 2012). Sociological investigation has traditionally highlighted the gendered, racialized, or class-structured nature of welfare policy and reform, in both process and outcome (von Oorschot 2006; Cebulla 2000, 2001); however, 
the processes and dynamics of risk and causation are often reduced to the individual level, and as such they are translated into direct personal and/or lifestyles and behaviours attributable to the individual 'at-risk' level. What exactly it is about race, gender, and class that actually contributes to welfare policy outcomes is not explored to the same extent. By using intersectionality as a frame for highlighting the complexities of oppression, the analysis of welfare policy can move beyond its current, frequently inadequate and inaccurate prediction of human risk vulnerability and behaviours. Intersectionality helps here because it highlights the importance of analysing marked as much as unmarked categories and how power, status and privilege, as well as disadvantage, are constituted (Crenshaw 1989).

Multi-layered concepts and multi-hierarchical models, joined to additive models of analysis, shed a more subtle light on the intersections of gender and race (Reingold and Smith 2012), gender and social class (Mandel 2012), and ethnicity, gender, and social class (Strand 2014, Penner and Saperstein 2013) in their relation to welfare policy design and outcome. The emerging research demonstrates that we cannot assume homogeneity within social identities, just as we have long understood not to assume homogeneity between them: it was black women who influenced the punitive character of US American welfare policy, not women per se; today's pension and retirement reforms disadvantage women relative to men; but amongst them it is the younger generations that appear at greatest risk of welfare loss (IRS 2011).

The identification of certain individuals as members of 'at-risk' groups without exploring or naming any of the structural forces that create certain groups, or their intersections, is problematic since 'at-risk' groups are connected to both implicit and explicit gender, racial, and class structures (Lupton 2012; Giritli Nygren and Fahlgren 2013). One example is the shift in Swedish labour market policy shown in public discourses and governmental documents, where not having full employment is framed as 'the greatest threat or risk', at the same time as interventions target communities with low socio-economic status and high ethnic diversity (Reg. 2011). Similar, whilst the UK government has been proised for introducing new measures to enhance the living conditions and economic integration of people with disability, it has also been criticised for framing the policy and tis reported outcomes in a prejudicial way that invokes negative perceptions of this population in the wider public (HOC 2014). A third example is the practice of back-towork activiation that confounds medical,, sociological and cultural typologies to rationalise activating and nealising interventions (Meershoek et al. 2011). The change, revealed in the individualized concept of being 'at risk', is that the responsibility is individualized, and thus renders any structural inequalities invisible, as if these power hierarchies no longer existed; as if they did not still prop up the structures of power, inequality, and injustice; as if women's and men's positions in the labour market do not differ; as if women's pay was not 80 per cent of men's; as if labour markets were not racialized and so on. In this sense, an intersectional analysis is of particular importance, in order to not render structural inequalities such as gender, class, and ethnicity invisible and non-politicized. After all, the identification of certain individuals as members of 'at-risk' groups without exploring or naming any of the structural forces that creates certain groups, often in direct comparison with others, is anyway connected to both implicit and explicit gender, racial, and class implications (Giritli Nygren \& Fahlgren 2013). 
A growing body of research has demonstrated the power of risk governance illustrated in the above brief examples and the complexities of new inequalities; however, theorizing in risk studies and social inequality has remained separate with few exceptions. In governmentality studies, and to some extent in socio-cultural studies, we find most of the research that has begun to employ a gender and even intersectional approach to risk (Hannah-Moffat and O'Malley 2007), while the work stemming from cultural theory, and particularly on the risk society, has not explored the continuities of social inequality to the same degree. By combining expertise in risk studies and intersectionality, we can clarify how new social inequalities are produced and reproduced through risk discourses and risk technologies. Altogether, by systematizing and analysing the findings derived from such research, we can contribute to a new understanding of how institutional changes and individual responses vary within and between different countries. Identifying certain general mechanisms behind the interconnections between risk governance and inequality, as well as explanations of their effects on the (re)production of social inequalities, would result in a theoretical advance and has obvious implications for social policy.

\section{Towards intersectional risk research}

New complexities and unexpected consequences arise from the fact that risk, rather than being a neutral, objective term, or a (reliable) measure of social problems, or the likelihood of crisis or disaster, is actually invested with values and beliefs that are as powerful in their normalizing force as the governance structures they permeate. The very idea of what constitutes a 'risk' articulates those values and beliefs, and does much to determine what people think, say, and do about that risk (Douglas 1992). The definition and anticipation of a 'risk' carries with it a sense of urgency or call for political action (Beck 2009; Wilkinson 2009). The 'language of risk' then becomes a discursive imperative, underwritten by its attendant values and beliefs. It offers a means to challenge accepted notions, promote special interests, and influence behaviour to attain a specific goal, or, by extension, to bring about specific forms of social change. Thus, risk (and its communication) creates a demand for changes in society and individuals. In this way, it may be viewed as involving the exercise of power, and may reveal the interactions of power relationships such as gender, class, and ethnicity.

Asking what it means for risk researchers to practise an intersectionality approach highlights the implications and complications of translating theoretical concepts from one study object or discipline to another. Previous attempts to apply an intersectional approach in public health and social medicine show that these studies are seldom related to theories of the ways in which the lived experience of oppression cannot be separated into single issues of class, race, and gender, or how it becomes intertwined with risks (Giritli Nygren and Olofsson forthcoming). With its basis in post-structuralist critiques of the subject as de-centred and its focus on the imbrications of multiple, differentially significant social categories, intersectionality offers a vantage point in this respect but at the same time it requires rethinking and redoing both of concepts and methods. We need to problematize standardized, 
quantitative calculative techniques to determine risks for particular social groups or individuals and the way decisions are made about interventions to deal with risky or at-risk groups and individuals informed by statistics (see Zinn 2013; Marston et al. 2010; Kemshall 2002). Such quantitative techniques are often intended to produce 'objective evidence', but in practice they are entangled with discourses that equate nominally average behaviour with desirable, normatively supported behaviour, framing deviations negatively - or even ignoring variations in individual or social experiences. Similarly, the production and selection of 'empirical' evidence is a highly political process, masked by discourses of objectivity (Boehm et al. 2013). Scholarly research often contradicts the claims made in public and political debates: consider the efficiency of surveillance technologies for preventing crime or convicting offenders, or the assumption that the threat of international terrorism is posed by external (Muslim) terrorists infiltrating 'civilized' countries. This results in a call for a shift away from decontextualized, objectivist examinations of risk and variable analysis to an active examination of the interrelation and interdependence of categories and variables in real life.

There is an urgent need to better understand the mutual constitution of risk and social inequality through societal discourses and practices. We have used a case study to show the need to understand how these conceptions reflect the intersections of age, gender, ethnicity, class, and risk and risk management. Research on risk using an intersectional approach promises to change our understanding of how broader socio-structural issues of gender, race, ethnicity, social class, and ability (mental health, substance abuse, and so on) are part of riskmanagement frameworks in institutional settings such as health, criminal justice, and education. It produces new knowledge about how different models of governance (re)define welfare risks, sanction private decisions and behaviours, and bring about new forms of (in)equity, solidarity, mutuality, and social distantiation. This in turn facilitates new knowledge about how regulatory practices relate to institutions and create new institutional assemblages. It changes our understanding of the operations of inclusion and exclusion through the processes of risk articulation and risk management. It also advances quantitative risk research by introducing theoretically well-informed intersectional approaches to social inequality that can help modify existing models of risk.

\section{References}

Amoore, L. and de Goede, M. 2008. Risk and the War on Terror. London: Routledge.

ASRC 2013. Asylum seekers and the right to work. ASRC Policy Position Paper: ASYLUM SEEKERS. Melbourne: Asylum Seeker Resource Centre.

Beck, U. 1992. Risk society: Towards a new modernity. London: SAGE.

Beck, U. 2009. World at Risk. Cambridge: Polity. 
Boehm, M., Bowman, D., Zinn, J. O. 2013. 'Survey Research and the Production of Evidence for Social Policy,' Social Policy and Society 12(2), pp.309-18.

Butler, J. 1990. Gender trouble: feminism and the subversion of identity. New York: Routledge.

Card, D., J. Kluve and A. Weber 2010. Active labour market policy evaluations: a metaanalysis. The Economic Journal, 120, F452-F477.

Cebulla, A. 2000. 'The final instance-Unemployment Insurance going private? A study of a future social security scenario in the UK and Germany', Innovation, (13), 4, 389-400.

Cebulla, A. 2001. 'Coping with risk: Attitudes towards private unemployment insurance in Britain and Germany', in: E. Schokkaert (ed.) Ethics and Social Security Reform, International Studies on Social Security Volume 7, Aldershot: Ashgate, pp. 165-182.

Cebulla, A, K. Ashworth, D. Greenberg and R. Walker. 2005. Welfare-to-Work. New Labour and the US Experience. Aldershot: Ashgate.

Choo, H. Y. and Ferree, M. M. 2010. 'Practicing intersectionality in sociological research: a critical analysis of inclusions, interactions and institutions in the study of inequalities.' Sociological Theory 28(2), 129-49.

Crenshaw, K. 2011. Twenty Years of Critical Race Theory: Looking Back To Move Forward. Connecticut Law Review, 43(5), 1253-1352.

Crenshaw, K. 1989. 'Demarginalizing the intersection of race and sex: a black feminist critique of antidiscrimination doctrine, feminist theory, and antiracist politics.' University of Chicago Legal Forum 139: 139-67.

Crisp, R. 2008. 'Motivation, morals and justice: discourses of worklessness in the welfare reform green paper'. People, Place and Policy online, 2/3: 172-85.

Cumming, S. and L. Caragata 2011. Rationing 'Rights': Supplementary Welfare Benefits and Lone Moms, Critical Social Work, (12) 1, 66-85.

Dean, M. 2006. The political mythology of world order; Carl Schmitt's nomos, Theory, Culture and Society, 23 (5), 1-21.

Dean, M. 1999. Governmentality—Power and Rule in the Modern Society. London: SAGE.

Dorey, P. 2010. A Poverty of Imagination: Blaming the Poor for Inequality. The Political Quarterly, (81) 3, 333-343. 
Douglas, M. 1992. Risk and Blame: Essays in Cultural Theory. London: Routledge.

Douglas, M. and Wildavsky, A. 1982. Risk and Culture: An essay on the selection of technical and environmental dangers. Berkeley \& Los Angeles: University of California Press.

Dworkin, S. L. 2006. 'Who is epidemiologically fathomable in the HIV/AIDS epidemic? Gender sexuality and intersectionality in public health.' Culture, Health and Sexuality: an International Journal for Research, Intervention and Care 7(6), 615-23.

Edge, D. 2013. 'Why are you cast down my, o my soul? Exploring intersections of ethnicity, gender, depression, spirituality and implications for black British Caribbean women's mental health.' Critical Public Health 23(1), 39-48.

Ferguson, R. A. 2012. Reading intersectionality. Trans-scripts, 2, 91-99.

Fetzer, J. S. 2011. The evolution of public attitudes towards migration in Europe and the United States: 2000-2010. EU-US Immigration Systems 2011/10. Robert Schuman Centre for Advanced Studies: European University Institute.

Finucane, M. L., Slovic, P., Mertz, C. K., Flynn, J. \& Statterfield, T. A. 2000. Gender, race, and percieved risk: The 'white male' effect. Health, Risk \& Society, 2(2), 159-172.

Frerichs, P. 2000. Klasse und Geschlecht asl Kategorien sozialer Ungleichheit. Kölner Zeitschrift für Soziologie und Sozialpsychologie 52(1), 36-59.

Giritli Nygren, K. and Fahlgren, S. 2013. Re-assembling 'the normal' in Neo-liberal times. Tracing (new) closures of 'normality' in the age of Risk. ESA 2013, 26-28 August, Turin, Italy

Giritli Nygren, K. and Olofsson, A. Forthcoming. Intersectional perspectives in health risk research-A critical review. Sociology Compass.

Hancock, A. M. 2007. 'When multiplication doesn't equal quick addition: examining intersectionality as a research paradigm.' Perspective on Politics 5(1): 63-79.

Hankivsky, O. and Christoffersen, A. 2008. 'Intersectionality and the determinants of health: a Canadian perspective.' Critical Public Health 18(3), 1-13.

Handler, J. 2004. Social Citizenship and Workfare in the United States and Western Europe: The paradox of inclusion, Cambridge: CUP.

Hannah-Moffat, K. and M. Lynch 2012. 'Theorizing punishment's boundaries'-Special issue of Theoretical criminology: An international Journal. 16 (2): 119-121. 
Hannah-Moffat, K. and O’Malley, P. (eds.) 2007. Gendered Risks. London: Routledge Cavendish.

Hannah-Moffat, K. 2004. 'Criminogenic Need and the Transformative Risk Subject: Hybridizations of Risk/Need in Penality.' Punishment and Society. 7 (1), 29-51.

Hannah-Moffat, K. 2010. 'Sacrosanct or flawed: Risk, Accountability and Gender-responsive Penal Politics'. Current Issues in Criminal Justice 22 (2), 193-216.

Hannah-Moffat, K. and Maurutto, P. 2010. 'Restructuring Pre-sentence Reports Race, Risk, and the PSR' Punishment and Society. 12(3), 262-286.

Maurutto, P and K. Hannah-Moffat. 2005. 'Assembling risk and the restructuring of penal control'. British Journal of Criminology. 45, 1-17.

Henne, K. and Troshynski. E. 2013. Mapping the Margins of Intersectionality: Criminological Possibilities in a Transnational World. Theoretical Criminology 17(4), 455-473.

HOC. 2014. Monitoring the performance of the Department for Work and Pensions in 201213. Third Report of Session 2013-14. HC1153. House of Commons Work and Pensions Committee. London: The Stationery Office Limited.

IRS. 2011. The socio-economic impact of pension systems on the respective situations of women and men and the effects of recent trends in pension reforms. Report for the European Commission. Milan: Istituto per la Ricerca Sociale.

Järvinen, M. 2012. A will to health? Drinking, risk and social class. Health, Risk \& Society. $14(3), 241-256$.

Joffe, H. 1999. Risk and 'the Other'. Cambridge: Cambridge University Press.

Kelly, P. 2007. Governing individualized risk biographies: New Class Intellectuals and the problem of youth at-risk. British Journal of Sociology of Education 28(1), 39-53

Kelly, P. 2010. The brain in the jar: troubling the truths of discourses of adolescent brain development, in unknown (ed.), TASA 2010 : Proceedings of the Annual Conference of The Australian Sociological Association, pp. 1-11, TASA, Sydney, N.S.W

Knapp, G-A. 2005. Race, Class, Gender. Reclaiming Baggage in Fast Travelling Theories. European Journal of Women's Studies 12(3), 249-265.

Le Grand, J. 1997. Knights, Knaves or Pawns? Human Behaviour and Social Policy. Jnl Soc. Pol., (26)2, 149-169. 
Lippman, A. 1999. Choice as a risk to women's health. Health, Risk \& Society. 1(3), 281291.

Lundström, R. 2013. Framing fraud: Discourse on benefit cheating in Sweden and the UK. European Journal of Communication 28(6), 630-645.

Lupton, D. 2012. Precious cargo. Critical Public Health 22(3): 329-40.

Marmot, M. 2004. Status syndrome: how your social standing directly affects your health and life expectancy. London: Bloomsbury.

Mandel, H. 2010. Winners and losers: The consequences of welfare state policies for gender wage inequality, European Sociological Review, 28 (2), 241-262.

McCall, L. 2005. 'The complexity of intersectionality.' Signs: Journal of Women in Culture and Society 30(3) 1771-1800.

McCall , L. 2001. Complex inequality. Gender, Class and race in the new economy. New York: Routledge.

Meershoek, A., A. Krumeich and Vos, R.2011. The construction of ethnic differences in work incapacity risks: analyzing ordering practices pf physicians in the Netherlands. Social Science \& Medicine, 72, 15-22.

Mirchandani, K., and Chan, W. 2007. Criminalizing Race, Criminalizing Poverty: Welfare Fraud Enforcement in Canada. Winnipeg: Fernwood.

Mitchell, E. 2013. I Am a Woman and a Human: A Marxist-Feminist Critique of Intersectionality Theory. Retrived at http://unityandstruggle.org/2013/09/12/i-am-a-womanand-a-human-a-marxist-feminist-critique-of-intersectionality-theory/.

Mythen, G. 2004. Ulrich Beck. A critical introduction to the risk society. London: Pluto.

O’Malley, P. 2004. Risk, Uncertainty and Government. Cavendish Press/Glasshouse: London.

Olofsson, A and Rashid, S. 2011a. The White (Male) Effect and Risk Perceptions: Can Equality Make a Difference? Risk Analysis. An International Journal, 31 (6) 1016-1032.

Olofsson, A and Rashid, S. 2011b. Social stratification, Living Conditions and the White Male Effect in Sweden. Sozialer Fortschritt. Unabhänige Zeitschrift fur Sozialpolitik. 60(3), 63-68. 
Penner, A. M. and Saperstein, A. 2013. Engendering Racial Perceptions: An Intersectional Analysis of How Social Status Shapes Race, Gender \& Society, 27(3), 319-344.

Piketty, T. 2013. Capital in the twenty-first century. Cambridge, Mass.: Belknap Press of Harvard University Press.

Piven, F. F. and R. A. Cloward, R. A. 1993. Regulating the poor: The functions of public welfare. London: Random House..

Prenzler, T. 2011. Welfare fraud in Australia: Dimensions and issues. Trends and Issues in Crime and Criminal Justice no. 421. Canberra: Australian Institute of Criminology.

Reg. 2011. 'Sweden's national reform program 2011-Europe 2020 - the EU's strategy for smart, sustainable and inclusive growth' (Government Offices of Sweden 2011).

Reignold, B and Smith, A. R. 2012. Welfare Policymaking and Intersections of Race, Ethnicity, and Gender in U.S. State Legislatures. American Journal of Political Science, 56(1), 131-147.

Rose, N. 1999. Powers of Freedom. Cambridge: CUP.

Rose, N. 2008. Race, risk and medicine in the age of 'your own personal genome'. BioSocieties 3(4): 425-441.

Sandberg, B. 1998. Sweden: Fraud and Abuse of Welfare Systems. Journal of Financial Crime, 5(4), 396-405.

Sassen, S. 1999. Whose City is It? Globalization and the Formation of New claims. In Ah Foong Foo, and Belinda K. P. Yuen Sustainable Cities in the 21th Century. Singapore: Faculty of Architecture, Building \& Real Estate, National University of Singapore.

Shamir, R. 2008. The age of responsibilization: on market-embedded morality, Economy and Society, 37(1), 1-19.

Signs, 2013. Intersectionality: Theorizing Power, Empowering Theory, (38)4

Skelton C. 2005. The 'individualized' (woman) in the academy: Ulrich Beck, gender and power, Gender and Education, 17:3, 319-332.

Standing, G. 2010. The Precariat: The New Dangerous Class. London: Bloomsbury Academic Press. 
Sutton, L, A. Cebulla, C. Heaver and N. Smith, 2004. Drugs and Alcohol as Barriers to Employment. A Review of the Literature. DWP Research Report W193A. Sheffield: Department for Work and Pensions.

Wacquant, L. 2009. Punishing the Poor: The Neoliberal Government of Social Insecurity. Duke University Press: Durham, NC.

Wall, E. 2014. Sense-making of risk and role-taking emotions: How young Swedes construe road traffic risk. Journal of Risk Research. On-line published: DOI 10.1080/13669877.2013.879487

Van Oorschot, W. 2006. Making the difference in social Europe: deservingness perceptions among citizens of European welfare states. Journal of European Social Policy 16(1): 23-42.

Wilkinson, I. 2009. Risk, Vulnerability and Everyday Life. London: Routledge

Zatz, Noah D. 2012. Poverty Unmodified? Critical Reflections on the Deserving/Undeserving Distinction. UCLA L. REV. 550, 550-597

Zinn, J. O. 2008. Introduction: The contribution of sociology to the discourse on risk and uncertainty. In Zinn, J. O. (ed.) Social Theories of Risk and Uncertainties: An Introduction. Malden: Blackwell.

Zinn, J. O. 2013. 'Introduction: Risk, Social Inclusion and the Life Course,' in Social Policy and Society 12(2), 253-64. 